nature

Volume 252

November 22, 1974

\section{Academics in the boardroom}

A FEW years ago a colleague working in a university was approached by an establishment of the Ministry of Defence with an invitation to become a consultant on some matters in which he was an expert. He underwent an extensive security grilling (the establishment had an unenviable record of leaks and was sensitive to recent criticism) and a year later was pronounced fit to be consulted. After the first few days at the site he returned to his university where several weeks later he was called by the head of the section for which he had consulted. "I'm terribly sorry to trouble you", he said, "but can you tell me whether you think your daily rate for consulting should be $£ 4, £ 7$ or $£ 10$ ?"

Is consultancy worth anything at all beyond those few pounds sterling either to industry or to universities at present? The question is touched lightly upon in The Universities and Applied Research, the proceedings of a day's symposium of industrialists and university scientists earlier this year, published by the Research and Development Society (47 Belgrave Square, London $\mathrm{SW} 1 ; £ 4.50$ ). The meeting was organised to look at the relevance of applied research in universities to social and industrial needs. One of the subjects which obviously came in for some attention was the ability of university staff to be responsive to industry-assuming they wished to-and there seemed to have been general agreement that consultancy was a good thing. Thus Professor G. V. R. Born (University of Cambridge) saw consultancy as "a fascinating assignment ... a less expensive way of providing industry with information and ideas [than taking similar persons on full-time]". And Professor K. Hoselitz (Mullard)-_"university consutlants (were) a useful way of forming a bridge". And Dr A. Spinks (ICI) "strongly approved of consultants". Can one therefore be satisfied that the consultancy system is an adequate means of broadening the understandings between industry and university, or is there more that could be done in the creation of formal machinery for the movement of highly intelligent people?

Despite the good intentions expressed above, there are many who regard consultancy cynically. On the university side there are those who give very poor value for money, who refuse to see industry in any broader perspective than that of the immediate problem presented to them or who dump the work on their students as unpaid sub-consultants. There are those who arrange with colleagues to provide mutually contradictory advice so that they can profit by regular recapitulation of the same opinion to a confused managing director.
On the industrial side there are many who employ consultants simply because it is a prestigious thing to do. Others do not use consultants for ideas or criticism but to provide an academic rubber stamp for their activities and a reassurance that they are not making asses of themselves.

Obviously the value of a consultancy depends entirely on the calibre of the two parties to it in each case, but there seems to be a need in many instances to go beyond the rather flimsy structure that the arrangement has at present. One of the biggest difficulties of an ad hoc scheme is that the consultant is insufficiently tied to the organisation for which he consults. He is not brought far enough into the corporate decision making nor the day-to-day running to feel deeply identified with the need for the company to be profitable. He is also likely to be fed problems which the company believes he might be able to solve - and which the company may have gone to some trouble to concoct for him-rather than be invited to roam around and pick up the problem that seems to him most important.

Many of those in applied research and a few of those in pure research in universities have had some industrial experience, but the number has been declining in recent years. Much of this experience, however, is at the junior scientific and technical level. What is now needed is more opportunities for the process of consultancy to move towards one in which it would be natural for senior university staff to consider a spell of up to several years in industry at the boardroom level. There is no doubt that many academics would find the industrial challenge stimulating and many industries would welcome new blood at the executive level. In addition the still rather distant relationships between industry and university in Britain could not but be helped by this.

The biggest problems are those man-made difficulties of tenure and pensions. It is ridiculous the extent to which careers become controlled by these constraints. There is hope that the quality of some pension schemes and their interchangeability will improve in the next year or two. The problem of university appointments remains and is not easily solved. It needs some imaginative thinking.

\section{A hundred years ago}

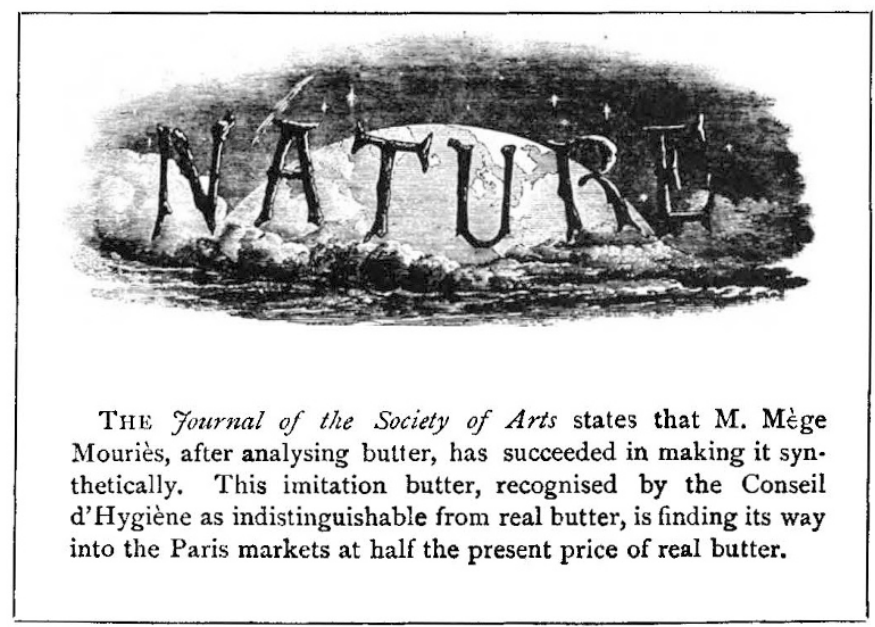

From Nature, 11, 76, November 26, 1874. 